\title{
ADAR expression and copy number variation in patients with advanced gastric cancer
}

\author{
Javad Behroozi ${ }^{1} \mathbb{B}$, Shirin Shahbazi ${ }^{*}$ (D), Mohammad Reza Bakhtiarizadeh² ${ }^{2}$ and Habibollah Mahmoodzadeh ${ }^{3}$ (D)
}

\begin{abstract}
Background: Gastric cancer (GC) is a world health problem and it is the third leading cause of cancer deaths worldwide. The current practice for prognosis assessment in GC is based on radiological and pathological criteria and they may not result in an accurate prognosis. The aim of this study is to evaluate expression and copy number variation of the ADAR gene in advanced GC and clarify its correlation with survival and histopathological characteristics.
\end{abstract}

Methods: Forty two patients with stage III and IV GC were included in this study. ADAR gene expression and copy number variation were measured by real-time PCR and Quantitative multiplex fluorescent-PCR, respectively. Survival analysis performed based on the Kaplan-Meier method and Mantel-Cox test.

Results: ADAR mRNA was significantly overexpressed in the tumor tissues when compared to the adjacent normal tissues $(p<0.01)$. Also, ADAR expression level in stage IV was higher than stage III. $40 \%$ of patients showed amplification in ADAR gene and there was a positive correlation between ADAR copy number and expression. Increased ADAR expression was clearly correlated with poorer survival outcomes and Mantel-Cox test showed statistically significant differences between low and high expression groups $(p<0.0001)$. ADAR overexpression and amplification were significantly associated with metastasis, size and stage of tumor.

Conclusions: Together, our data indicate that amplification leads to over expression of ADAR and it could be used as a prognostic biomarker for disease progression, especially for the metastatic process in GC.

Keywords: Gastric cancer, ADAR gene, Overexpression, Amplification, Prognosis

\section{Background}

Gastric cancer (GC) currently ranks fourth in cancer incidence worldwide. Gastric adenocarcinoma is the most common histological type of all malignancies originating in the stomach and known as a heterogeneous disease with diverse phenotypes and genotypes. Although in the last few decades its prevalence has declined to reach a plateau, GC still is the third leading cause of cancer

\footnotetext{
* Correspondence: sh.shahbazi@modares.ac.ir

'Department of Medical Genetics, Faculty of Medical Sciences, Tarbiat Modares University, Tehran, Iran

Full list of author information is available at the end of the article
}

deaths worldwide [1]. Surgery is the most helpful and reliable procedure to eradicate the disease, especially in the case of primary tumors. Nevertheless, the results for advanced GC remain unfavorable even when extensive surgery had been performed [2]. Studies from several groups over the past decade have now produced a nearcomprehensive catalogue of genetic alterations in GC [3]. Certain genetic and epigenetic molecular abnormalities such as tumor suppressor gene mutations, gene changes inducing loss of normal cellular adhesion, overexpression or mutations of cell membrane receptors with tyrosine kinase activity or activation of angiogenic

(c) The Author(s). 2020 Open Access This article is licensed under a Creative Commons Attribution 4.0 International License, which permits use, sharing, adaptation, distribution and reproduction in any medium or format, as long as you give appropriate credit to the original author(s) and the source, provide a link to the Creative Commons licence, and indicate if changes were made. The images or other third party material in this article are included in the article's Creative Commons licence, unless indicated otherwise in a credit line to the material. If material is not included in the article's Creative Commons licence and your intended use is not permitted by statutory regulation or exceeds the permitted use, you will need to obtain permission directly from the copyright holder. To view a copy of this licence, visit http://creativecommons.org/licenses/by/4.0/ The Creative Commons Public Domain Dedication waiver (http://creativecommons.org/publicdomain/zero/1.0/) applies to the data made available in this article, unless otherwise stated in a credit line to the data. 
factors have been reported to be involved in the pathogenesis and progression of GS $[4,5]$.

RNA editing is an important form of post-transcriptional processing, which can alter RNA molecules by deamination of adenosine to form inosine. This reaction is catalyzed by a family of enzymes named adenosine deaminase acting on RNA (ADARs) [6]. The human genome contains three ADAR genes including ADAR, ADARB1 and ADARB2. The first two are ubiquitously expressed and catalytically active, but, ADARB2 exclusively expressed in the brain and has not shown any catalytic activity so far [7]. Although both ADAR and ADARB1 have been shown to play roles in tumorigenesis, most of cancer related editing events regulated by ADAR, primarily due to more abundant expression of ADAR and its unique features [8].

It is estimated that human transcriptome undergoes over 100 million editing events, which may result in codon changes with the consequence of altered protein function, alternative splicing or affect targeting and maturation of microRNAs [9]. ADAR with the ability to change DNA-encoded genetic information after transcription, could be an important contributor in cancer development [10]. Hence, the inconsistency in ADAR expression or activity may be a causative factor in a variety of diseases including cancer [11]. Amplification and overexpression of the ADAR gene occurs in over $8 \%$ of breast, lung, and hepatic cancers [12].

Acute myeloid leukemia was the first cancer that altered mRNA editing was shown to be connected to the disease [8]. Thereafter, ongoing studies have been elucidate role of ADAR in cancer development and progression. It has been shown that increased ADAR expression correlates with tumor recurrence in lung adenocarcinoma [13]. In addition, ADAR overexpression is connected with increased malignancy of breast, lung and liver cancer, and silencing of ADAR in breast cancer cells results in increased apoptosis. The latter suggests that ADAR has anti-apoptotic function that promotes cancer progression [14].

Although significant progress has been made in the management and treatment of GC patients, however, further studies should be conducted to promises discoveries of new biomarkers and more innovative and effective treatments for patients with GC. The main end point of our study is to evaluate expression and copy number variation of ADAR (ADAR1) gene in advanced GC and clarify its correlation with overall survival and histopathological characteristics.

\section{Methods}

\section{Patients and specimen collection}

Fresh frozen tumor and normal adjacent tissue of 42 patients with stage III and IV gastric adenocarcinoma who underwent surgery at the Cancer Institute of Iran were examined in this study. We included only GC patients that did not receive neoadjuvant therapy. The biological materials were provided by the Iran National Tumor Bank, founded by the Cancer Institute of Tehran University of Medical Sciences, for cancer research. Staging were based on the American Joint Committee on Cancer (AJCC) cancer staging manual [15]. All samples were transferred in liquid nitrogen from Tumor bank and stored at $-80^{\circ} \mathrm{C}$ for further investigations. Complete clinicopathologic data including patient history, histology, clinical, and paraclinical data and follow-up information were gathered from the medical records of every patient. All participants signed written informed consent.

\section{RNA/DNA extraction}

RNA and DNA were purified from normal and tumoral samples using the All-in-one DNA/RNA/Protein MiniPreps Kit (Biobasic, Canada) following manufacturer's protocol. The RNA quality was verified by electrophoresis on $1.0 \%$ agarose gel. Also, the quantity of isolated RNA and DNA was evaluated by NanoPhotometer (NP80, Germany).

\section{CDNA synthesis and real-time PCR}

RNA samples were reverse transcribed into complementary deoxyribonucleic acid (cDNA) using Easy ${ }^{\mathrm{mm}}$ cDNA Synthesis Kit (Parstous biotechnology, Iran). The cDNA was synthesized from $1 \mu \mathrm{g}$ of total RNA with random hexamer and oligo $(\mathrm{dT})$ as reaction primers in a final volume of $20 \mu \mathrm{l}$ following manufacturer's protocol.

Obtained cDNA was further amplified by real-time quantitative PCR using RealQ Plus Master Mix Green (Ampliqon, Denmark) based on the kit protocol. The primers used for performing real-time PCR were as follows: for ADAR1 F: 5'AGCTTGGGAACAGGGAATCG3' and R: 5'CTTCGCAGTCTGGGAGTTGT3'; for GAPDH F: 5' ACACCCACTCCTCCACCTTTG3' and R: 5'TCCACCACCCTGTTGCTGTAG3'. Real-time PCR mixture contained $10 \mu \mathrm{l}$ of SYBR green master mix, $1 \mu \mathrm{l}$ of forward and reverse primers and $2 \mu \mathrm{l}$ of cDNA. Real-time PCR program for the reaction was based on a holding step at $95^{\circ} \mathrm{C}$ for 15 min, followed by 40 cycles of denaturing at $95^{\circ} \mathrm{C}$ for $20 \mathrm{~s}$, annealing and extending at $60^{\circ} \mathrm{C}$ for $40 \mathrm{~s}$. Real-time PCR was performed at least three times in the StepOne ${ }^{\mathrm{T \omega}}$ RealTime PCR System (Applied Biosystems, USA) for each sample and fold change of gene expression was calculated using $2^{-\Delta \Delta \mathrm{Ct}}$ method.

\section{Quantitative multiplex fluorescent-PCR (QMF-PCR)}

The ADAR gene copy number was quantified by QMFPCR on a BIOER XP Cycler (Bioer, China). The QMFPCR technique consists of the quantification of fluorescently labeled test and control amplicons, obtained by a single multiplex PCR amplification. Primers were 
designed for 5'UTR, exonic and 3'UTR of the ADAR gene. Three other genes including BOD1L, AGBL2 and POR were co-amplified as controls. A tail of universal primer was added to forward primers, except for POR gene which the tail was added to reverse primer. The universal primer was labeled with the fluorescent phosphoramidite 6-FAM dye and all the primers were HPLC purified. Multiplex PCR employed the Multiplex TEMPase Master Mix (Ampliqon, Denmark) following the manufacturers recommendations. Primers stock solution was prepared in a 0.5:1:0.5 ratio of forward primer, reverse primer and fluorescently tagged universal primer, respectively. The reaction started with an initial denaturation of $15 \mathrm{~min}$ at $95^{\circ} \mathrm{C}$, followed by 30 cycles at $95^{\circ} \mathrm{C}$ for $45 \mathrm{~s}, 59.8^{\circ} \mathrm{C}$ for $45 \mathrm{~s}$ and $72{ }^{\circ} \mathrm{C}$ for $45 \mathrm{~s}$, and a final extension of $15 \mathrm{~min}$ at $72{ }^{\circ} \mathrm{C}$. Primer sequences used for QMF-PCR are shown in Table 1.

One $\mu \mathrm{l}$ of the PCR products was added to $10 \mu \mathrm{l}$ of formamide and $0.5 \mu \mathrm{l}$ of GeneScan-500 LIZ size standard (Applied Biosystems, USA). Then, the PCR product was denatured at $95^{\circ} \mathrm{C}$ for $3 \mathrm{~min}$ and placed on ice to prevent re-annealing until further analysis. Fragment analyses were performed using a POP7 gel on the ABI 3500 Genetic Analyzer (Applied Biosystems, USA). The results were processed with GeneMarker software V2.7 (SoftGenetics, USA) to obtain electropherograms for each sample. Each product was identified by its size, and the area under peak were imported into an Excel spreadsheet and the copy number of each amplicon was determined by calculating a dosage quotient (DQ) for each fragment $[16,17]$.

\section{Cell lines ADAR gene expression and CNV}

Biological databases are crucial for exploring the molecular mechanisms of cancer, therefore, basal expression of ADAR mRNA and ADAR copy number in 37

Table 1 List of primer sequences used for QMF-PCR analysis in this study. Universal tail was shown in bold letters

\begin{tabular}{lll}
\hline Gene & Primer Sequence \\
\hline ADAR-3'UTR & F & GCCTCCCTCGCGCCATAGACTTGGTGCCGTGGTGA \\
& R & GTCGCAGAGCCTCAGTAGTC \\
ADAR-Exonic & F & GCCTCCCTCGCGCCATCGACTTGTAACCGGCCTGA \\
& R & GTTGTAAACGACCCAGACGG \\
ADAR-5'UTR & F & GCCTCCCTCGCGCCAGGGGACCACTTACAAGCTGATG \\
& R & GTCTGGTCGCAGATTGGTGA \\
AGBL2 & F & GCCTCCCTCGCGCCAGCGAGCTGCATTCCATGCG \\
& R & TCCCAGCTTTGGAACGCAC \\
BOD1L & F & GCCTCCCTCGCGCCAAATGCCTCCGCTTTCAGGC \\
& R & ATCACTTGGCAACTCACACATGG \\
POR & F & AGCCACTTGTGCCAGATCA \\
& R & GCCTCCCTCGCGCCATCCAGCACGTGTTCACATCA \\
Universal & $U$ & FAM-GCCTCCCTCGCGCCA \\
\hline
\end{tabular}

GC cell lines were obtained from cancer cell line Encyclopedia (CCLE) [18]. RNA expression values were reported in reads per kilobase of transcript per million mapped reads (RPKM). Finally, the association of the RNA expression values and gene copy numbers for each cell line was examined.

\section{Survival analyses}

To investigate the relationship between ADAR expression and prognosis of gastric cancer, survival data associated with GC patients were obtained from Kaplan-Meier Plotter [19]. Overall survival (OS) data for 876 patient (312 low expression and 564 high expression) were analyzed to create Kaplan-Meier plots. These patients were related to GSE14210, GSE15459, GSE22377, GSE29272, GSE51105 and GSE62254 datasets.

\section{Statistical analyses}

All statistical analyses were performed using SPSS 18.0 (SPSS Inc., USA) and GraphPad Prism 8 (GraphPad Software, USA) software. Paired T-test was applied in comparisons of ADAR mRNA levels between GC tissue samples and their paired non-tumor counterparts and unpaired T-test was used for comparison between stage III and IV. The Chi-square test was performed to evaluate correlations between ADAR expression or amplification and clinicopathological parameters. Pearson's correlation coefficient was used to determine the relationship between the expression and CNV of ADAR in GC cell lines. Differences in the OS between the high and low expression groups were estimated and compared by the Kaplan-Meier method with a Mantel-Cox test. Differences were considered significant when the $P$ value was $<0.05$.

\section{Results}

\section{ADAR gene expression in gastric cancer tissue}

Among the 42 tumor specimens tested, average expression of ADAR mRNA was significantly upregulated in the tumor tissues when compared to the adjacent normal tissues of the GS patients $(p<0.01$, Fig. 1$)$. In tumor samples ADAR was expressed 2.8-fold higher than normal tissues. That is to say, the level of ADAR mRNA expression was increased in $32(76.2 .0 \%)$ tumors while it was decreased in $6(14.3 \%)$ cases and it has remained unchanged in 4 (9.5\%) tumors (Fig. 1b). The average expression of ADAR mRNA was lower in the stage III in comparison to stage IV ( $p=0.0225$, Fig. 1c).

\section{ADAR copy number variation}

According to DQ of the three segments of ADAR gene, we divided ADAR CNV into deleted, amplified and diploid categories (Fig. 2). Our results showed 20 (40\%) tumors with diploid copy number, 5 (12\%) tumors with 
A

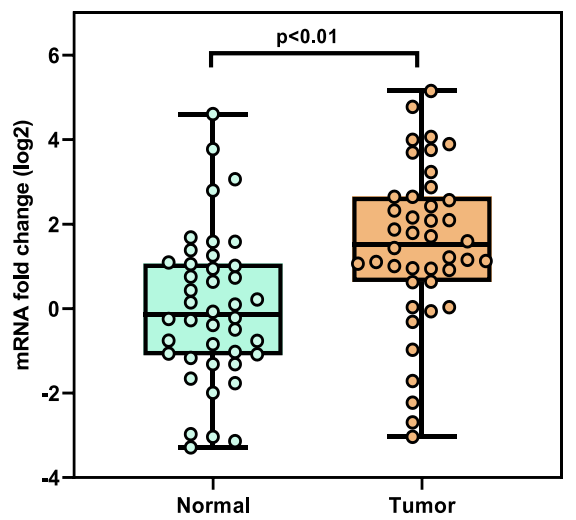

C

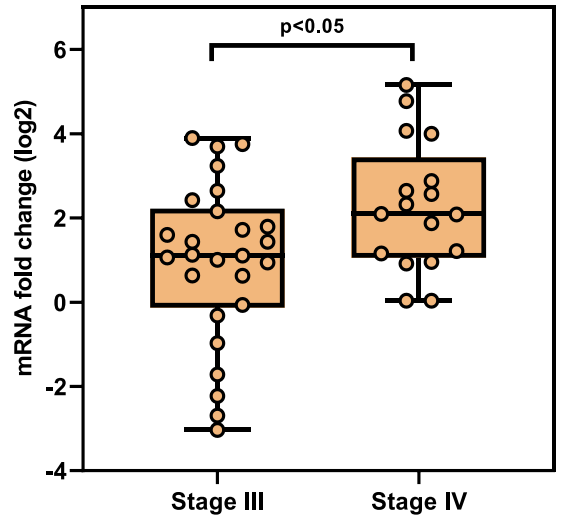

B

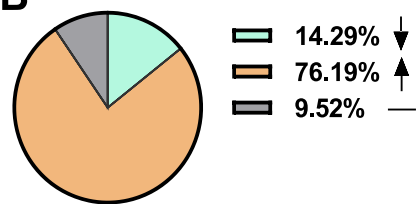

Fig. 1 ADAR gene expression in GC patients (a) matched normal and tumor tissues, (b) percent of ADAR dysregulation, (c) stage IIIC compared with Stage IV

deleted and 17 (40\%) tumors with amplified ADAR gene. Patients with amplification showed significant increase in ADAR gene expression compared with patients with diploid and deleted ADAR copy number (Fig. 3a). Analysis of ADAR copy number in GC cell line were consistent with tumor specimens. We found a positive correlation $(\mathrm{r}=0.61, p<0.0001)$ between ADAR copy number and expression (Fig. 3b).

\section{Correlations between ADAR expression and CNV with clinicopathological features}

Here, we analyzed the association of the ADAR gene $\mathrm{CNV}$ and its expression with the clinicopathological features of patients. Forty two tissue samples based on ADAR gene expression were classified into 2 groups: high expression (FC $>4.56, n=17$ ) and low expression (FC $\leq 4.56, n=25)$. This study consisted of 25 patients aged $\geq 66$ years and 17 patients aged $<66$ years $(P=$ $0.573)$. ADAR high expression was significantly associated with metastasis $(p=0.008)$, stage $(p=0.008)$, histology $(p=0.015)$ and size of tumor $(p=0.004)$. Moreover, amplification was significantly associated with metastasis $(p<0.018)$, stage $(\mathrm{p}<0.018)$ and size of tumor $(p=0.008)$ in GC patients and tended to be associated with histology $(p=0.143)$. Furthermore, no significant association was detected between ADAR gene CNV and its expression and other clinicopathological parameters, including age, gender, regional lymph node metastases, site of primary tumor and Lymphovascular invasion (Table 2).

\section{Prognostic value of ADAR in gastric cancer}

The GC database used in this study, includes 876 samples from six independent datasets. Kaplan-Meier analysis of this dataset indicated that increased ADAR expression was clearly correlated with poorer survival outcomes (Fig. 4). Patients in the high expression group had a significantly shorter OS than patients in the low expression group (log-rank test, $P<0.0001$ ). Median survival of high and low expression groups were 23.2 and 70.2 months, respectively. Furthermore, median survival of patients with different characteristics was obtained. Patients with high expression of ADAR have significantly lower median survival time in most subgroups (Table 3 ).

\section{Discussion}

Application of molecular biomarkers in clinical setting might improve diagnostic and management strategy of GC patients. To date, some molecular markers, including human epidermal growth factor receptor-2, vascular endothelial growth factor receptor 2, urothelial cancer associated 1, excision repair crosscomplementation group 1, B-cell lymphoma-2, and Ki-67 have been proposed to have diagnostic and prognostic value in the management of GC patients $[20,21]$. However, the majority of these markers were not able to accurately reflect prognostic value and 


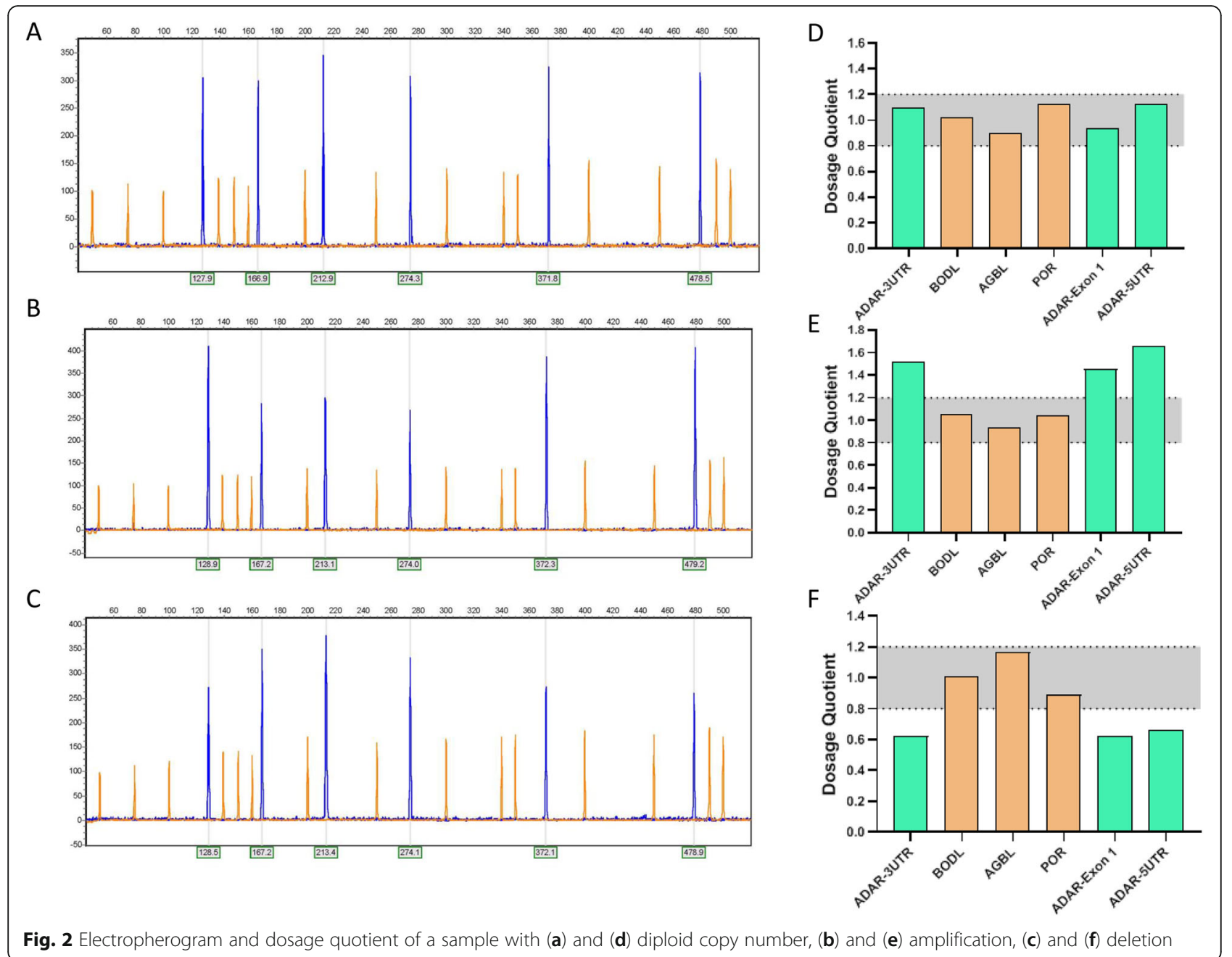

therapeutic efficiency in advanced GC. Identification of molecular biomarkers might improve patient therapeutic strategy of GC, hence, we evaluated the CNV and expression of ADAR to reveal its alteration and clinical significance in advanced GC.
We analyzed mRNA expression level of ADAR in GC tumors and adjacent normal tissues. This revealed that ADAR is remarkably overexpressed in GC tumors. In addition, we compared ADAR expression level in GC stage III and IV. Interestingly, the average expression of
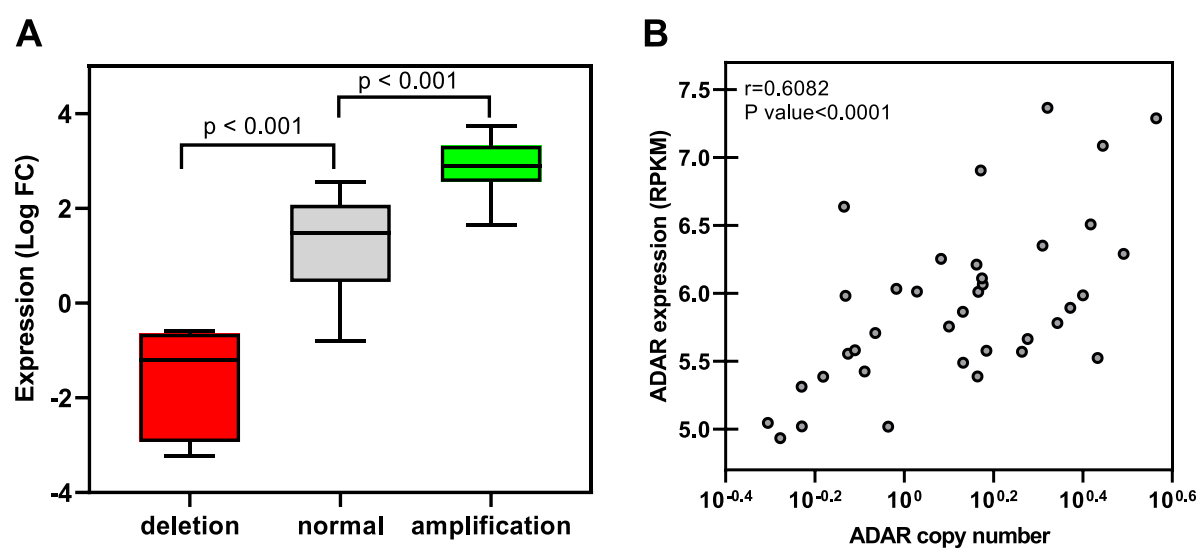

Fig. 3 Correlation of CNV and gene expression in GC patients (a) patients and (b) GC cell lines 
Table 2 Correlation between clinicopathological variables and ADAR expression and CNV in Gastric cancer patients

\begin{tabular}{|c|c|c|c|c|c|c|}
\hline \multirow[t]{2}{*}{ variable } & \multicolumn{2}{|c|}{ ADAR expression } & \multirow[t]{2}{*}{$\boldsymbol{P}$ value } & \multicolumn{2}{|c|}{ ADAR amplification } & \multirow[t]{2}{*}{$\boldsymbol{P}$ value } \\
\hline & $\operatorname{High}(17)$ & $\operatorname{Low}(25)$ & & Yes(18) & $\mathrm{No}(24)$ & \\
\hline \multicolumn{7}{|l|}{ Age (year) } \\
\hline$\geq 66^{\mathrm{a}}$ & 11 & 14 & 0.573 & 11 & 14 & 0.856 \\
\hline$<66$ & 6 & 11 & & 7 & 10 & \\
\hline \multicolumn{7}{|l|}{ Gender } \\
\hline Male & 11 & 15 & 0.758 & 12 & 14 & 0.582 \\
\hline Female & 6 & 10 & & 6 & 10 & \\
\hline \multicolumn{7}{|l|}{ Pathological $\mathrm{N}$ category } \\
\hline NO & 1 & 1 & 0.074 & 1 & 1 & 0.086 \\
\hline N1 & 1 & 4 & & 0 & 5 & \\
\hline N2 & 5 & 15 & & 8 & 12 & \\
\hline N3 & 10 & 5 & & 9 & 6 & \\
\hline \multicolumn{7}{|l|}{ M classification } \\
\hline MO & 6 & 19 & $0.008^{*}$ & 7 & 18 & $0.018^{*}$ \\
\hline M1 & 11 & 6 & & 11 & 6 & \\
\hline \multicolumn{7}{|l|}{ Site of primary tumor } \\
\hline Antrum & 4 & 6 & 0.937 & 4 & 6 & 0.315 \\
\hline Body & 8 & 13 & & 9 & 12 & \\
\hline Cardia & 4 & 4 & & 5 & 3 & \\
\hline Fundus & 1 & 2 & & 0 & 3 & \\
\hline \multicolumn{7}{|l|}{ Histology } \\
\hline Well differentiated & 0 & 5 & $0.015^{*}$ & 1 & 4 & 0.143 \\
\hline Moderately differentiated & 3 & 11 & & 4 & 10 & \\
\hline Poorly differentiated & 10 & 8 & & 9 & 9 & \\
\hline Undifferentiated & 4 & 1 & & 4 & 1 & \\
\hline \multicolumn{7}{|l|}{ Size of primary tumor } \\
\hline$<6.1$ & 7 & 21 & $0.004^{*}$ & 8 & 20 & $0.008^{*}$ \\
\hline$\geq 6.1$ & 10 & 4 & & 10 & 4 & \\
\hline \multicolumn{7}{|l|}{ Tumor stage } \\
\hline Stage 4 & 11 & 6 & $0.008^{*}$ & 11 & 6 & $0.018^{*}$ \\
\hline Stage 3 & 6 & 19 & & 7 & 18 & \\
\hline \multicolumn{7}{|l|}{ Lymphovascular invasion } \\
\hline Present & 14 & 16 & 0.196 & 15 & 15 & 0.139 \\
\hline Absent & 3 & 9 & & 3 & 9 & \\
\hline
\end{tabular}

${ }^{*}$ indicates $p$-value $<0.05 .{ }^{a}$ the median age at surgery was 66 years

ADAR mRNA in stage IV was higher than stage III. Besides, overexpression of ADAR was significantly associated with metastasis, stage, histology and size of tumor, which may indicate that ADAR has a pivotal role in stage III to IV progression of GC. According to ADAR function, overexpression of ADAR could leads to hyperediting [22]. Unbalanced editing process has adverse results, and abnormal RNA editing within the transcriptome detected in many kinds of tumors. RNA editing could leads to recoding of a transcript and contribute to carcinogenesis through reducing the activity of tumor suppressors such as bladder cancer associated protein in hepatocellular carcinoma [23] or enhancing the activity of pro-survival genes such as antizyme inhibitor 1 in cervical cancer [24].

To determine whether ADAR copy number has variation in tumors, QMF-PCR was conducted. We found that ADAR significantly amplifies in advanced GC. Moreover, our results showed a positive correlation between ADAR gene copy number and its expression at 


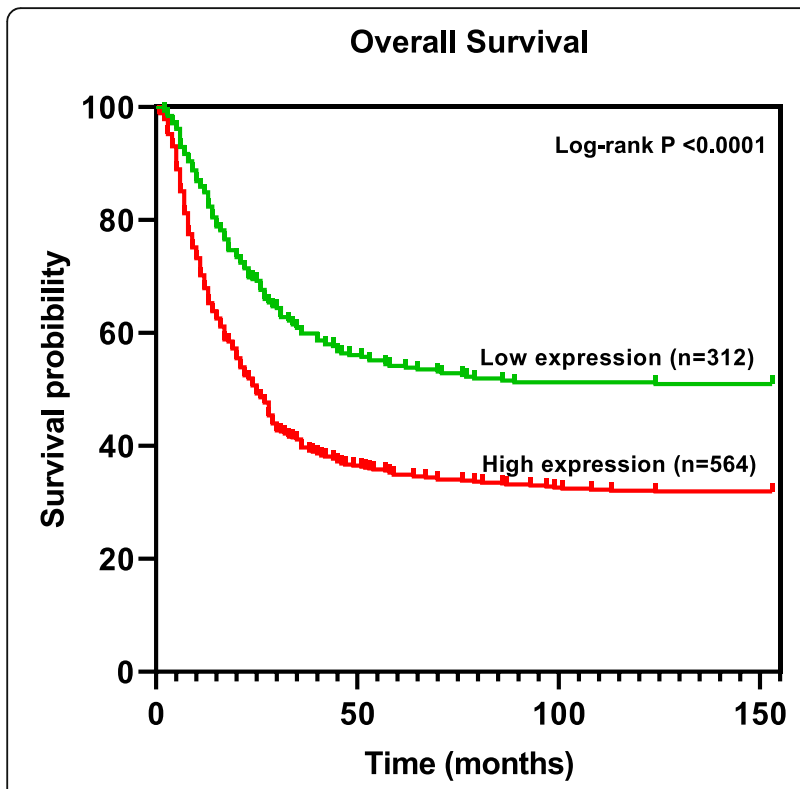

Fig. 4 Kaplan-Meier survival curves according to high and low expression of ADAR

the mRNA level. Correlation between ADAR copy number and ADAR expression has also been reported in breast carcinoma, ovarian adenocarcinoma, lung adenocarcinoma and liver carcinoma [24]. ADAR frequently amplifies in human cancers consistent with the elevated expression and editing levels of its substrates [25]. Notably, knockdown of ADAR in lung adenocarcinoma cells with amplified ADAR leads to decreased migration and invasion [13]. Hence, pharmacological targeting of ADAR promise a potential therapeutic application for tumors with ADAR amplification.

Also, we carried out a correlation test between ADAR expression and copy number change in 37 GC cell lines and statistical analysis revealed that ADAR expression was consistently associated with ADAR copy number. The association of gene copy number with gene expression has also been found in other cancer cell lines. Hyman et al. performed a high-resolution analysis in breast cancer cell lines and showed that $44 \%$ of the highly amplified genes showing overexpression and $10.5 \%$ of the highly overexpressed genes being amplified [26]. These findings further strengthen our hypothesis that ADAR amplification increases its expression.

As previously mentioned, ADAR amplification and overexpression in different cancers have been reported $[24,25]$. Yet, the effects of these genomic and transcriptomic changes on clinicopathological features of GC patients have remained largely unknown. We evaluated the association of the ADAR gene $\mathrm{CNV}$ and its expression with the clinicopathological features of patients. The mRNA expression levels of ADAR were positively associated with metastasis, stage, histology and size of tumor.

Table 3 Characteristics and median survival of patients in high and low expression groups

\begin{tabular}{|c|c|c|c|}
\hline \multirow[t]{2}{*}{ Characteristics } & \multicolumn{2}{|c|}{ Median survival (months) } & \multirow[t]{2}{*}{ Log-rank P } \\
\hline & High expression & Low expression & \\
\hline \multicolumn{4}{|l|}{ Gender } \\
\hline Male $(n=544)$ & 20.3 & 32.1 & $1.6 \mathrm{e}-5$ \\
\hline Female $(n=236)$ & 15.2 & 93.2 & $4.3 e-7$ \\
\hline \multicolumn{4}{|l|}{ Tumor stage } \\
\hline Stage $1(n=67)$ & $N A^{a}$ & NA & - \\
\hline Stage $2(n=140)$ & 29 & 78.6 & 0.103 \\
\hline Stage $3(n=305)$ & 22.4 & 52.6 & $2 e-4$ \\
\hline Stage $4(n=148)$ & 17.5 & 15.93 & 0.148 \\
\hline \multicolumn{4}{|l|}{ Histology } \\
\hline Well differentiated $(n=32)$ & 14.5 & 45.1 & 0.053 \\
\hline Moderately differentiated $(n=67)$ & 30.4 & 56.9 & 0.428 \\
\hline Poorly differentiated $(n=165)$ & 23.6 & 40 & 0.105 \\
\hline \multicolumn{4}{|l|}{ Lauren classification } \\
\hline Intestinal $(n=320)$ & 25.9 & 99.4 & $3.1 e-5$ \\
\hline Diffuse $(n=241)$ & 27.8 & 40 & 0.038 \\
\hline Mixed $(n=32)$ & 57.2 & 20.9 & 0.041 \\
\hline \multicolumn{4}{|l|}{ Treatment } \\
\hline Surgery $(n=380)$ & 45.8 & 85.6 & 0.217 \\
\hline 5-Fluorouracil $(n=152)$ & 9.2 & 21.3 & $3.3 e-6$ \\
\hline
\end{tabular}

${ }^{a}$ NA means no death in follow up threshold 
Indeed, ADAR amplification was significantly associated with metastasis, stage and size of tumor. Findings of the current study support the previous study reporting the oncogenic potential of ADAR in GC [27]. The association between the tumor aggressiveness and the overexpression of ADAR has also been demonstrated in hepatocellular carcinoma and colorectal cancer [28, 29]. Based on available evidences, the molecular mechanisms of how ADAR promotes GC cell growth and migration might be explained by its role in the regulation of mTOR signaling pathway. Overexpression of ADAR in GC cells increases proliferation and migration but these effects significantly debilitate with rapamycin, the mTOR kinase inhibitor, demonstrating that rapamycin could inhibit the effects of ADAR overexpression on GC cell growth and migration. Together these results suggested that mTOR signaling is important for ADAR mediated GC invasion and metastasis [27].

Currently, prognosis of GC patients is primarily determined using depth of wall invasion, lymph node or distant metastasis status and age; however, these prognostic factors are limited in clinical practice, and may not result in an accurate prognosis [30]. To further confirm the prognostic value of ADAR overexpression in GC patients, Kaplan-Meier analysis and log-rank test were performed. The results showed that the overall survival rate of patients with lower expression of ADAR was better than that of patients with high expression, suggesting its prognostic role. Chen et al. found a correlation between high expression of ADAR and a poor prognosis of cervical cancer [24]. Again, Chan et al. showed a significant correlation between ADAR upregulation and GC patient shorter survival [31].

\section{Conclusions}

The current study demonstrates that ADAR mRNA is overexpressed in GC through DNA copy number amplification. ADAR overexpression and amplification correlate with the main negative clinicopathological factors such as metastasis, tumor size and stage in GC patients. Furthermore, increased ADAR expression was clearly correlated with poorer survival outcomes. Therefore, ADAR overexpression is not only a biomarker of tumor progression but also contributes to tumor progression. We propose ADAR as useful prognostic markers and therapeutic targets for GS. Doubtless, further investigations are necessary to confirm these primary results.

\section{Abbreviations}

GC: Gastric cancer; ADAR: Adenosine deaminase acting on RNA; CDNA: Complementary deoxyribonucleic acid; QMF-PCR: Quantitative multiplex fluorescent-PCR; CNV: Copy number variation; OS: Overall survival; DQ: Dosage quotient

\section{Authors' contributions}

The study concept and design involved SS, MRB and JB. Access to biological material provided by HM. SS and JB were responsible for the recruitment and data collection. Data analysis was completed by SS and JB. JB drafted the original manuscript. The article was revised by SS, MRB and HM. All authors read and approved the final version.

\section{Funding}

This work was supported by the Tarbiat Modares University and Iran National Science Foundation (grant number: 97014362). The funders had no role in the study design, data collection, and data analysis, interpretation of data and writing of the manuscript.

\section{Availability of data and materials}

The datasets used and/or analyzed during the current study are available from the corresponding authors upon reasonable request.

\section{Ethics approval and consent to participate}

This study was approved by Ethics Committee of Tarbiat Modares University with IR.MODARES.RES.1397.205 Code of ethics. All patients provided written informed consent, and the study was conducted in accordance with the Declaration of Helsinki.

Consent for publication

Not applicable.

\section{Competing interests}

The authors declare no competing interests.

\section{Author details}

'Department of Medical Genetics, Faculty of Medical Sciences, Tarbiat Modares University, Tehran, Iran. ${ }^{2}$ Department of Animal and Poultry Science, College of Aburaihan, University of Tehran, Tehran, Iran. ${ }^{3}$ Department of Surgical Oncology, Cancer Institute, Imam Khomeini Hospital Complex, Tehran University of Medical Sciences, Tehran, Iran.

Received: 22 January 2020 Accepted: 7 May 2020

Published online: 14 May 2020

\section{References}

1. Ajani JA, Lee J, Sano T, Janjigian YY, Fan D, Song S. Gastric adenocarcinoma. Nat Rev Dis Primers. 2017;3:17036.

2. Terashima M, Maesawa C, Oyama K, Ohtani S, Akiyama Y, Ogasawara S, et al. Gene expression profiles in human gastric cancer: expression of maspin correlates with lymph node metastasis. Brit J Cancer. 2005:92(6):1130.

3. Tan P, Yeoh KG. Genetics and molecular pathogenesis of gastric adenocarcinoma. Gastroenterology. 2015;149(5):1153-62.

4. Cervantes A, Braun ER, Fidalgo AP, González IC. Molecular biology of gastric cancer. Clin Transl Oncol. 2007:9(4):208-15.

5. Fan XY, Hu XL, Han TM, Wang NN, Zhu YM, Hu W, et al. Association between RUNX3 promoter methylation and gastric cancer: a meta-analysis. BMC Gastroenterol. 2011;11(1):92.

6. Yang $Y$, Zhou $X$, Jin Y. ADAR-mediated RNA editing in non-coding RNA sequences. Sci China Life Sci. 2013:56(10):944-52.

7. Gal-Mark N, Shallev L, Sweetat S, Barak M, Li JB, Levanon EY, et al. Abnormalities in A-to-l RNA editing patterns in CNS injuries correlate with dynamic changes in cell type composition. Sci Rep. 2017;7(1):1-12.

8. Xu LD, Öhman M. ADAR1 editing and its role in Cancer. Genes. 2019;10(1): 12.

9. Deffit SN, Hundley HA. To edit or not to edit: regulation of ADAR editing specificity and efficiency. WIREs RNA. 2016;7(1):113-27.

10. Kung CP, Maggi LB Jr, Weber JD. The role of RNA editing in cancer development and metabolic disorders. Front Endocrinol. 2018:9:762.

11. Zhang Y, Qian $H, X u J$, Gao W. ADAR, the carcinogenesis mechanisms of ADAR and related clinical applications. Ann Transl Med. 2019;7(22):686.

12. Herbert A. ADAR and immune silencing in Cancer. Trends Cancer. 2019;5(5): 272-82

13. Amin EM, Liu Y, Deng S, Tan KS, Chudgar N, Mayo MW, et al. The RNAediting enzyme ADAR promotes lung adenocarcinoma migration and invasion by stabilizing FAK. Sci Signal. 2017;10(497):eaah3941. 
14. Fritzell $K$, Xu LD, Otrocka M, Andréasson C, Öhman M. Sensitive ADAR editing reporter in cancer cells enables high-throughput screening of small molecule libraries. Nucleic Acids Res. 2018;47(4):e22.

15. Gershenwald J, Scolyer R, Hess K, Thompson J, Long G, Ross M, et al. AJCC cancer staging manual. Switzerland: Springer; 2017. p. 563-89.

16. McCord BR, Butler JM. The application of capillary electrophoresis in the analysis of PCR products used in genetic typing. New Jersey: Humana Press; 2001. p. 261-84.

17. Gay-Bellile M, Romero P, Cayre A, Véronèse L, Privat M, Singh S, et al. ERCC1 and telomere status in breast tumours treated with neoadjuvant chemotherapy and their association with patient prognosis. J Pathol Clin Res. 2016;2(4):203-20.

18. Barretina J, Caponigro G, Stransky N, Venkatesan K, Margolin AA, Kim S, et al, The Cancer cell line encyclopedia enables predictive modelling of anticancer drug sensitivity. Nature. 2012:483(7391):603.

19. Szász AM, Lánczky A, Nagy Á, Förster S, Hark K, Green JE, et al. Crossvalidation of survival associated biomarkers in gastric cancer using transcriptomic data of 1,065 patients. Oncotarget. 2016;7(31):49322-33.

20. Zheng Q, Wu F, Dai WY, Zheng DC, Zheng C, Ye H, et al. Aberrant expression of UCA1 in gastric cancer and its clinical significance. Clin Transl Oncol. 2015;17(8):640-6.

21. Liu J, Liu Z, Zhang X, Gong T, Yao D. Bioinformatic exploration of OLFML2B overexpression in gastric cancer base on multiple analyzing tools. BMC Cancer. 2019;19(1):227.

22. Okugawa Y, Toiyama Y, Shigeyasu K, Yamamoto A, Shigemori T, Yin C, et al. Enhanced AZIN1 RNA editing and overexpression of its regulatory enzyme ADAR1 are important prognostic biomarkers in gastric cancer. J Transl Med. 2018;16(1):366.

23. Hu X, Wan S, Ou Y, Zhou B, Zhu J, Yi X, et al. RNA over-editing of BLCAP contributes to hepatocarcinogenesis identified by whole-genome and transcriptome sequencing. Cancer Lett. 2015;357(2):510-9.

24. Chen $Y$, Wang $H$, Lin W, Shuai P. ADAR1 overexpression is associated with cervical cancer progression and angiogenesis. Diagn Pathol. 2017;12(1):12.

25. Paz-Yaacov N, Bazak L, Buchumenski I, Porath HT, Danan-Gotthold M, Knisbacher BA, et al. Elevated RNA editing activity is a major contributor to transcriptomic diversity in tumors. Cell Rep. 2015;13(2):267-76.

26. Hyman E, Kauraniemi P, Hautaniemi S, Wolf M, Mousses S, Rozenblum E, et al. Impact of DNA amplification on gene expression patterns in breast cancer. Cancer Res. 2002;62(21):6240-5.

27. Dou N, Yu S, Ye X, Yang D, Li Y, Gao Y. Aberrant overexpression of ADAR1 promotes gastric cancer progression by activating mTOR/p70S6K signaling. Oncotarget. 2016;7(52):86161-73.

28. Chen L, Li Y, Lin CH, Chan TH, Chow RK, Song Y, et al. Recoding RNA editing of AZIN1 predisposes to hepatocellular carcinoma. Nat Med. 2013; 19(2):209-16.

29. Shigeyasu K, Okugawa Y, Toden S, Miyoshi J, Toiyama Y, Nagasaka T, et al. AZIN1 RNA editing confers cancer stemness and enhances oncogenic potential in colorectal cancer. JCl insight. 2018:3(12):e99976.

30. Han J, Tu J, Tang C, Ma X, Huang C. Clinicopathological characteristics and prognosis of cT1NOM1 gastric Cancer: a population-based study. Dis Markers. 2019;2019:5902091.

31. Chan TH, Qamra A, Tan KT, Guo J, Yang H, Qi L, et al. ADAR-mediated RNA editing predicts progression and prognosis of gastric cancer. Gastroenterology. 2016;151(4):637-50

\section{Publisher's Note}

Springer Nature remains neutral with regard to jurisdictional claims in published maps and institutional affiliations.

Ready to submit your research? Choose BMC and benefit from:

- fast, convenient online submission

- thorough peer review by experienced researchers in your field

- rapid publication on acceptance

- support for research data, including large and complex data types

- gold Open Access which fosters wider collaboration and increased citations

- maximum visibility for your research: over $100 \mathrm{M}$ website views per year

At $\mathrm{BMC}$, research is always in progress.

Learn more biomedcentral.com/submissions 